\title{
Síndrome do jaleco branco em crianças na emergência: estudo descritivo
}

\section{White coat syndrome in children in the emergency department: a descriptive study}

DOI: $10.46919 / \operatorname{archv2n6-004~}$

Recebimento dos originais: 01/06/2021

Aceitação para publicação: 31/07/2021

\section{Silvia Helena Oliveira Da Cunha}

Enfermeira do Hospital Universitário Antônio Pedro/HUAP. Mestranda do Programa de Mestrado Profissional em Enfermagem Assistencial/MPEA da Escola de Enfermagem Aurora de Afonso e Costa da Universidade Federal Fluminense/UFF. Niterói (Rio de Janeiro), Brasil.

E-mail: olivershoc@yahoo.com.br

\section{Eliane Ramos Pereira}

Enfermeira. Doutora em Enfermagem. Pós-doutorado/UERJ. Professora do Programa de Mestrado Profissional Enfermagem Assistencial/MPEA da Escola de Enfermagem Aurora de Afonso e Costa da Universidade Federal Fluminense/UFF. Niterói (Rio de Janeiro), Brasil.

E-mail: elianeramos.uff@gmail.com

\section{Rose Mary Costa Rosa Andrade Silva}

Enfermeira. Filósofa. Doutora em Enfermagem. Professora Associada do Departamento de Enfermagem Médico Cirúrgica da Escola de Enfermagem Aurora de Afonso e Costa da Universidade Federal Fluminense/UFF. Niterói, (Rio de Janeiro), Brasil.

E-mail: rafamig@terra.com.br

\section{Daniela Chaves Costa}

Graduanda em Enfermagem e Licenciatura da Escola de Enfermagem Aurora de Afonso e Costa da Universidade Federal Fluminense/UFF. Niterói, (Rio de Janeiro), Brasil.

E-mail: danichcosta@gmail.com

\section{Vivian Moreira Mencari}

Enfermeira. Universidade Federal Fluminense. Niterói (Rio de Janeiro), Brasil. E-mail: vivianmencari@ hotmail.com

\section{RESUMO}

O momento na hospitalização da criança gera uma mudança brusca na vida de uma família, pois envolvem circunstâncias, como a interrupção do cotidiano, onde ela se vê longe de seus irmãos, do pai e amigos; de seu lar e de seus hábitos. É um evento social que mobiliza todos, tem seu caráter segregante, pois afasta a criança e sua família da vida em sociedade, mas por outro lado, tem-se o desafio de conhecer novos ambientes, outras pessoas e por que não dizer, a possibilidade de fazer amizades e de retornar ao lar com a saúde restaurada. A criança hospitalizada passa por todo este processo e precisa do suporte familiar e educativo, a fim de que entenda aos poucos o processo no qual está inserida. Objetivos: descrever o fenômeno de extremo medo apresentado pela criança quando está na presença do jaleco branco. Visa também, apontar contribuições na minimização de manifestações de medo extremo e da síndrome do jaleco branco em crianças. Método: Estudo descritivo, com abordagem qualitativa e adotando conceitos da visão fenomenológica desenvolvido no setor de emergência pediátrica de um hospital universitário. Utilizou-se a técnica da entrevista semiestruturada, evocações livres e observação participante com treze familiares, a fim de produzir dados acerca da cultura do medo reproduzida pela família nas crianças hospitalizadas. 
Resultados: Os dados foram submetidos à análise de Bardin, onde se estabeleceram cinco categorias: Profissionais de saúde; objetos estranhos; evento indesejável; infecções e bactérias hospitalares e medo da morte da criança. Detectou-se o fenômeno de intenso medo pela criança comparado à "síndrome do jaleco branco em adultos" no qual foi interpretado sob o ponto de vista fenomenológico. Conclusão: Concluiu-se que a articulação de estratégias terapêuticas, é ferramenta indispensável tanto na prevenção da síndrome do jaleco branco em crianças, quanto no fortalecimento do estado de resiliência e no enfrentamento do medo pela criança e família.

Descritores: Enfermagem Pediátrica; Enfermagem em Emergência; Saúde da Criança; Família; Medo.

\begin{abstract}
The moment a child is hospitalized generates an abrupt change in the life of a family, because it involves circumstances, such as the interruption of daily life, where the child is far from his/her siblings, father and friends; from his/her home and habits. It is a social event that mobilizes everyone; it has its segregating character, as it distances the child and his family from life in society, but on the other hand, there is the challenge of getting to know new environments, other people, and why not say, the possibility of making friends and returning home with his health restored. The hospitalized child goes through this whole process and needs family and educational support, so that he/she can gradually understand the process in which he/she is inserted. Objectives: to describe the phenomenon of extreme fear presented by the child when in the presence of the white coat. It also aims to point out contributions to minimize manifestations of extreme fear and the white coat syndrome in children. Method: A descriptive study, with a qualitative approach and adopting concepts from the phenomenological view, developed in the pediatric emergency department of a university hospital. We used the technique of semi-structured interview, free evocations and participant observation with thirteen family members, in order to produce data about the culture of fear reproduced by the family in hospitalized children. Results: The data were submitted to Bardin analysis, where five categories were established: health professionals; foreign objects; undesirable event; hospital infections and bacteria and fear of the child's death. The phenomenon of intense fear for the child was detected, compared to the "white coat syndrome in adults", which was interpreted from a phenomenological point of view. Conclusion: It was concluded that the articulation of therapeutic strategies is an indispensable tool both in the prevention of white coat syndrome in children and in the strengthening of the state of resilience and coping with fear by the child and the family.
\end{abstract}

Descriptors: Pediatric Nursing; Emergency Nursing; Child Health; Family; Fear.

\title{
1 INTRODUÇÃO
}

O choro da criança é uma linguagem primitiva que vai além do gestual, pois envolve emoção e necessidades, com a conquista da articulação da linguagem falada, o choro tornou-se uma manifestação que para a família, é assustadora e por vezes, complicada, pois demanda observação e interpretação por parte dos adultos. Dessa forma, o choro da criança em ambiente hospitalar pode ser, em virtude não apenas de suas necessidades humanas básicas, mas também, oriundas dos fatores hospitalares que a estressam, que podem e devem ser atenuados pelos profissionais de saúde, principalmente pelos profissionais de enfermagem, porque são os que mais tempo interagem com a criança e sua família.

$\mathrm{O}$ ato de proferir um som inarticulado típico, para comunicar ou expressar um sentimento, ou um desejo de atenção ${ }^{(1)}$. O choro é o principal recurso de comunicação de bebês menores de três meses. Por 
meio do choro, os bebês expressam dor, fome, raiva e tédio, mas às vezes choram sem nenhuma razão em particular.

Mesmo bebês saudáveis que são muito bem cuidados choram muito. Nos três primeiros meses de vida, cerca de $25 \%$ dos bebês choram mais de três horas e meia por dia. Por volta dos três meses de idade, os bebês começam a chorar menos ${ }^{2}$. Começam a balbuciar e movem-se com mais facilidade, e são capazes de expressar-se de outras maneiras além do choro. Choro persistente e aparentemente sem motivo pode fazer com que os pais sintam-se preocupados, irritados ou incompetentes. Todos os bebês passam por fases em que o choro é excessivo, inesperado e inconsolável, mas aqueles que vivenciam muito essa experiência (cerca de $10 \%$ a $20 \%$ ) são chamados às vezes de bebês com cólicas ${ }^{(2)}$.

Portanto, o choro é uma linguagem primitiva que vai além do gestual, pois envolve emoção e necessidades e com a conquista da articulação da linguagem falada, o choro tornou-se uma manifestação que para o adulto é assustadora e por vezes complicada, porque demanda observação e interpretação.

Esta expressão na criança está intimamente ligada à insegurança, dor e desconforto, é uma linguagem universal que os mamíferos têm como forma de expressão e escape na presença do sofrimento. Ele expressa a inquietação da criança com alguém ou algo, presente ou ausente, o que é saudável, concomitante à inquietação gerada no adulto que se vê preocupado em saciar o apelo da criança. Portanto, é desafiador saber o que está acontecendo com a criança quando está chorando. Ele mobiliza os adultos a observar mais e a ser sensível em sua percepção em identificar o que está acontecendo com a criança.

Socialmente, o choro é interpretado "negativamente" por muitas culturas, no qual representa implicitamente fraqueza humana, pois se espera uma conduta "forte" sem emoções, quando não, somente emoções "positivas". Mas para o familiar da criança, o choro representa dor, sofrimento e algo que ela quer, ou está sentindo algo, que eles ainda não descobriram o que possa ser, o que demanda dele, mais observação baseado na vivência e conhecimento sobre as atitudes da criança.

Quando as crianças são hospitalizadas, estas reagem, principalmente, à separação materna, por ser este o primeiro vínculo afetivo. Também descrevem que esta reação também é em relação à separação da família, do lar, à lesão corporal e à dor, pelo fato de estarem doentes e de continuar recentemente adquiridos (3).

Dessa forma, o choro da criança em ambiente hospitalar é a primeira reação expressa e visível no processo de hospitalização, não sendo somente em virtude de suas necessidades humanas básicas, mas de origem intrínseca da criança e também, oriundas dos fatores hospitalares que a estressam podendo ser atenuados pelos profissionais de saúde, principalmente pelos profissionais de enfermagem, pois são os que mais tempo interagem com a criança e sua família. 


\section{MÉTODO}

Trata-se de um estudo descritivo, do tipo relato de experiência, com abordagem qualitativa a respeito do fenômeno da síndrome do jaleco branco em crianças internadas durante a práxis do cuidado de enfermagem desde 1994 até os dias atuais. O cenário foi o setor de Emergência Pediátrica do Hospital Universitário Antônio Pedro da Universidade Federal Fluminense (HUAP/UFF), no município de Niterói, RJ.

A luz de conceitos da fenomenologia e da observação participante durante o cuidado com as crianças hospitalizadas na emergência pediátrica, o presente relato de experiência, vem sugerir estratégias lúdicas e mais humanas, atenuando o medo em excesso, no qual é o gatilho do surgimento da síndrome do jaleco branco em crianças e promover o enfrentamento da dor, do medo e do sofrimento, inclusive favorecer o fortalecimento emocional.

A fenomenologia é a "ciência dos fenômenos", entendendo por fenômeno o que se mostra no seu ser de si mesmo à consciência, o que é, pois, imediatamente dado em si mesmo à consciência ${ }^{(4-5)}$.

A pretensão da fenomenologia consiste em não separar o sujeito do fenômeno, mas reúne-los de maneira indissolúvel, na estrutura da experiência intencional, o homem e o mundo, o sujeito e o objeto, a existência e significação. Dessa forma, esses fenômenos são objetos gerados a partir de experiências e vivências das pessoas, mais especificamente suas essências (existência e significação). O sujeito será a fonte geradora do fenômeno e este sempre terá algo a dizer sobre o sujeito. Por isso, deve-se "perguntar" ao fenômeno: “o que ele quer dizer?” Para que seja possível obter respostas para a questão supramencionada, é preciso conhecer as variáveis que compõem o estudo de um fenômeno: sua essência, sua intuição e sua intencionalidade. Isso porque o fenômeno está no discurso existencial de cada pessoa e não pode ser descrito com uma única palavra, pois sua definição engloba um discurso. E, por mais que o discurso humano seja inesgotável, ele tende a ser suficiente para gerar um resultado, uma resposta ${ }^{(5)}$.

Ressalta-se que não foi necessária a submissão ao Comitê de Ética e Pesquisa da instituição, por se tratar de um relato de experiência, no qual busca trazer uma proposta mais humana e lúdica aos profissionais, familiares da criança e instituição envolvida, a partir da dinâmica e da vivência referente à Emergência Pediátrica, levando em consideração a visão fenomenológica a respeito da síndrome do jaleco branco em crianças internadas. Por conseguinte, descrevemos a experiência através da observação participante, na qual foi percebido o sofrimento e a expressão de extremo medo, dificultando o cuidado de enfermagem oferecido à criança, principalmente em se tratando de procedimento doloroso e invasivo.

Dessa forma, mudar a abordagem, primeiramente com a família, a fim de melhor cuidar da criança, é a estratégia educativa, possível e eficaz na conquista da parceria no cuidado. A família em sua dimensão cuidadora e educativa replica o conhecimento que adquire por toda vida. A prevenção de sequelas emocionais também faz parte do cuidado, inclusive a compreensão da realidade, explicar a criança o que 
está acontecendo e o que irá acontecer, sem fantasias, ou inverdades, pode parecer trabalhoso e pouco importante para muitos, mas é necessário para sua compreensão e colaboração durante o cuidado de enfermagem.

\section{RESULTADOS}

\subsection{MANIFESTAÇÕES DO MEDO EXTREMO QUE MUDA O COMPORTAMENTO DA CRIANÇA.}

O medo como um fenômeno psíquico, de caráter afetivo. O medo é um estado emocional que resulta da tomada de consciência de que algo real, imaginário ou provocado pode ameaçar os indivíduos. A reação ao medo é acompanhada de indicadores fisiológicos que se manifestam de acordo com seu grau de intensidade. O medo será assim, à semelhança da ansiedade e da angústia, um sentimento de inquietação, de preocupação, dada a possibilidade de que algo desagradável possa ocorrer ${ }^{(6)}$.

Sabe-se que o medo e o sofrimento é uma experiência única, individual e de caráter intrínseco, mas que pode ser aliviado com atitudes por parte dos adultos que sejam educativas e terapêuticas, desse modo, durante a observação participante, percebeu-se o fenômeno de extremo sofrimento e dor emocional, no entanto, em algumas situações, observa-se que a família diz à criança frases ameaçadoras que dificultam a colaboração dela, aumentando o medo e sofrimento. Percebe-se que na criança, a dor emocional vem antes da dor física, inclusive antes do procedimento ocorre uma manifestação extrema de reação contrária e de protesto em relação à dor iminente, no entanto, no momento da dor propriamente dita, muita das vezes, é observada pouca reação, e por vezes, ocorre a expressão facial de decepção por ela pensar que sentiria muito mais dor.

Conforme as entrevistadas (codinome de flores) a seguir, percebe-se o medo sentido pela criança representado em suas falas (em itálico e negrito) quando a criança (inicial do nome abreviada) vê o profissional de saúde com jaleco branco.

só em ver vocês
quando aconteceu
tinha médico
entendeu?

cai a saturação,

ela fica com pavor.

ficar, com certeza.

Eu sei porque meu
Hortência - Ah, sente ... com certeza! Sente porque o H., antigamente, ele assim de branco, já gritava e vocês nem chegavam perto. Tanto é, que aquilo com um aninho, quando ele veio transferido aqui do quinto andar, que tirava o jaleco, ou se não, esperava ele dormir pra poder "escutá-lo", Porque senão eles não conseguiam. Porque ele chorando, altera a pressão, então descontrola tudo. Então, não adianta nem mexer na criança, porque Isso é da criança que fica muito internada, assim direto, se eles ficam. Deve Mas igual a quem já fica internada muito tempo, realmente tem esse mesmo. 
lo, senão não

filho gritava. Tinha médico que tinha que tirar o jaleco para poder examiná-

conseguia.

nada. Eu acho que é

Dália - É o jaleco branco. Ele tem pavor, acho que é isso. Tem mais

Getulinho ele trouxe, ou viu o

quando ele vê essas roupinhas brancas passando ... Desde lá do

enfermeiro passando, ele ... no dia que outra pessoa vinha falar com ele,

de um dia pro outro,

vinha com aquela

eu comecei a observar ele, tivesse sem roupa, ele ia até no colo, aí quando

tem medo do jaleco

roupa, ele já fazia, retraiu na hora, então, ele tem medo, acho que ele

branco sim (risos de Dália).

Hortência - "Ah, sente... com certeza! Sente porque o H., antigamente, ele só em ver vocês assim de branco, já gritava e vocês nem chegavam perto. Tanto é, que quando aconteceu aquilo com 1 aninho, quando ele veio transferido aqui do $5^{\circ}$ andar, tinha médico que tirava o jaleco, ou se não, esperava ele dormir pra poder "escutá-lo", entendeu? Porque senão eles não conseguiam. Porque ele chorando, altera a pressão, cai a saturação, então descontrola tudo. Então não adianta nem mexer na criança, porque ela fica com pavor. Isso é da criança que fica muito internada. Fica com esse medo. Eu não sei se essas crianças que não é internada assim direto, se eles ficam. Deve ficar, com certeza. Mas igual a quem já fica internada muito tempo, realmente tem esse mesmo. Eu sei porque meu filho gritava. Tinha médico que tinha que tirar o jaleco pra poder examiná-lo, senão não conseguia”. Data da entrevista: 26/08/14.

Observação participante: Nota-se que quando há a aproximação para aferir a temperatura axilar de H., mesmo dentro de sua limitação neurológica (sequela de choque anafilático), apresentava uma agitação motora, a saturação descia, apresentando rubor facial e piscava com muita frequência quando as pessoas com jaleco branco se aproximavam dele, sendo necessário a mãe e o profissional conversarem muito com ele, ainda que seja somente para colocar o termômetro sob a axila.

Hortência - “Ah, sente... com certeza! Sente porque o H., antigamente, ele só em ver vocês assim de branco, já gritava e vocês nem chegavam perto. Tanto é, que quando aconteceu aquilo com 1 aninho, quando ele veio transferido aqui do $5^{\circ}$ andar, tinha médico que tirava o jaleco, ou se não, esperava ele dormir pra poder "escutá-lo”, entendeu? Porque senão eles não conseguiam. Porque ele chorando, altera a pressão, cai a saturação, então descontrola tudo. Então não adianta nem mexer na criança, porque ela fica com pavor. Isso é da criança que fica muito internada. Fica com esse medo. Eu não sei se essas crianças que não é internada assim direto, se eles ficam. Deve ficar, com certeza. Mas igual a quem já fica internada muito tempo, realmente tem esse mesmo. Eu sei porque meu filho gritava. Tinha médico que tinha que tirar o jaleco pra poder examiná-lo, senão não conseguia”. Data da entrevista: 26/08/14.

Observação participante: Notei que quando me aproximei para aferir a temperatura axilar de $H$., mesmo dentro de sua limitação neurológica (sequela de choque anafilático), apresentava uma agitação motora, a saturação descia, apresentando rubor facial e piscava com muita frequência quando as pessoas com jaleco branco se aproximavam dele, sendo necessário a mãe e o profissional conversarem muito com ele, ainda que seja somente para colocar o termômetro sob a axila.

Dália - "É o jaleco branco. Ele tem pavor, acho que é isso. Tem mais nada. Eu acho que é quando ele vê essas roupinhas brancas passando...Desde lá do Getulinho ele trouxe, ou vi o enfermeiro passando, ele... no dia que outra pessoa vinha falar com ele, de um dia pro outro eu comecei a observar ele, tivesse sem roupa, ele ia até no colo, aí quando vinha com aquela roupa, ele já fazia, retraiu na hora, então, ele tem medo, acho que ele tem medo do jaleco branco sim (risos)". Data da entrevista: 23/10/14. 
Observação participante: Quando me aproximei para entrevistar a Dália, vi que seu filho D. estava acordado no berço brincando com os brinquedos do setor. Quando ele notou a minha presença começou a chorar, querendo ir para o colo da mãe como forma de fuga e de proteção. De alguma forma se sentiu ameaçado, ela falava com ele e eu também, mas ele queria o colo, ele só acalmou quando ela deu o peito para ele mamar.

Gardênia - [...] ele não é de chorar, mais assim, muita das vezes ele chora porque ele acha que vai ficar longe da gente, medo, eu logo imagino que ele está sentindo dor, que ele está sofrendo muito, mas muita das vezes eu acho que é medo da parte dele”. Data da entrevista: 17/09/14.

Observação participante: A criança K. estava no colo da mãe, quando me aproximei deles com jaleco, ele que estava sentado colocou-se de pé e abraçou a mãe ficando de costas para mim, chorava, a face ficou com rubor, pois gritava e suava muito, no entanto, quando ele viu que eu não pretendia fazer nada doloroso com ele, porque estava apenas conversando com a mãe, K. foi se acalmando e aos poucos foi diminuindo o chora até eu ir embora.

Nota-se que as entrevistas foram realizadas em épocas diferentes de internação, não havendo comunicação entre as participantes. Percebe-se que o medo do jaleco branco está presente na criança e que precisa ser desconstruído, pois pode representar dano psicológico, traumas e doenças psicossomáticas. O medo apontado pelas mães, leva-nos a reflexões sobre o significado construído e existente no jaleco branco tanto para crianças, quanto para seus familiares. O branco representa o somatório de cores que se anulam e se tornam em uma única cor que é o branco, ou seja, no branco não há estímulos visuais, pois as cores integram o mundo, ajudando na distinção de objetos e fenômenos. Ao ver o jaleco branco, parece que a criança reconhece o medo e a experiência dolorosa vivenciada no hospital. Nota-se que a criança aprende a ter medo das pessoas que vestem o jaleco branco criança aprende a ter medo de que estiver vestido de jaleco branco desde o início da vida. Parece haver uma analogia, entre o jaleco branco à dor, ao medo, ao sofrimento, no qual ela já conhece e que é inevitável.

Por muitas vezes, percebemos que independente da realização de procedimentos dolorosos, os familiares amedrontam as crianças com a imagem da injeção, do hospital e do profissional de enfermagem, a fim de obter o controle do seu comportamento, inclusive sua colaboração em procedimentos. O desafio da Enfermagem está na desconstrução da imagem do medo associado ao profissional de enfermagem trajado com jaleco branco, sua função social e com o real motivo dela estar ali, a doença.

Quando ocorre a aproximação de alguém trajado com jaleco branco, com o termômetro para por sob as axilas na aferição da temperatura. Observou-se em várias crianças lactentes e pré-escolares, que estas apresentavam sinais e sintomas reação adrenérgica, com reação de luta e fuga, viravam seus rostos, suavam extremamente, apresentavam rubor facial, agarravam-se ao pescoço de seus familiares, choravam com lágrima e gritavam muito, corriam para o banheiro, mas não apresentavam eliminações fisiológicas, em outras, já ocorria liberação de esfíncter, tentavam fugir, mas a possibilidade da fuga da situação de dor e sofrimento que representava ter alguém de jaleco branco, não era possível, por se tratar de uma necessidade real. 
Esquema representativo da reprodução social do medo. Niterói/Rio de Janeiro, 2014.

\section{REPRODUÇÃO SOCIAL DO MEDO}

ESTADO

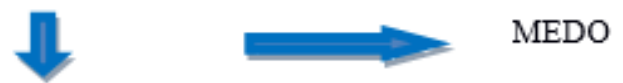

CONTROLE SOCIAL

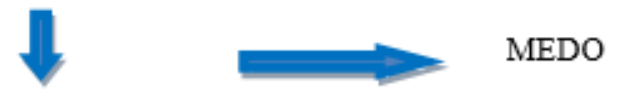

VIOLÊNCIA

SOCIEDADE
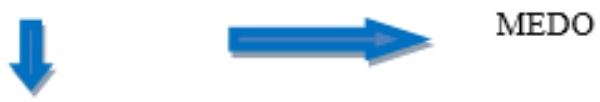

INSEGURANÇA

INDIVÍDUO

MEDO

(AMEAÇA VERBAL)

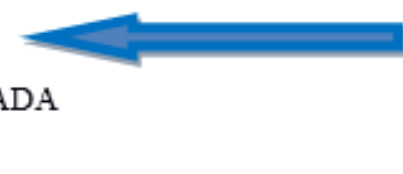

1

FAMÍLIA

(BARGANHA PELA PUNIÇÃO)

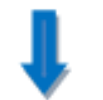

ESTRESSE PSICOLÓGICO

(CASTIGO)

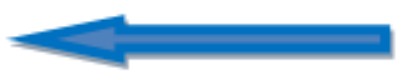

CRIANÇA

CHORO

MEDROSA,

INSEGURA E

INCONTIDO (ESTRESSE PSICOLÓGICO)

DESCONFIADA

TRAUMAS?

FOBIAS?

DOENÇAS

PSICOSSOMÁTICAS?

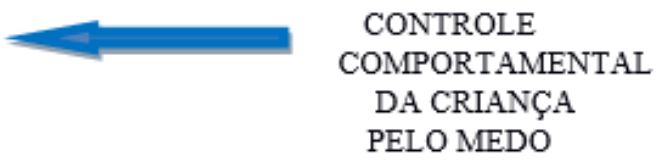

CONTROLE

DA CRIANÇA

PELO MEDO

Fonte: Construído pela autora em 2014 e adaptado em 2015.

\subsection{A CULTURA DO MEDO REFORÇADA PELOS ADULTOS.}

Como o medo é uma emoção socialmente controlada, a vergonha surge como mecanismo social de condicionamento à sua própria expressão. Gera-se, pois, neste campo, um paradoxo que não deixa de ter repercussões não só no equilíbrio emocional, como também no cognitivo e comportamental. Neste sentido, a questão do medo social não deixa de ser um problema de saúde mental. Saúde mental visto que o medo 
social é um medo existencial que resulta de uma situação de insegurança e de vulnerabilidade, fragiliza o ser humano e retira-lhe a disponibilidade para se sentir bem consigo próprio ${ }^{(6)}$.

O medo do jaleco branco em crianças é real, sendo observado e verbalizado pelas mães, o branco representa a ausência de estímulos. O branco representa o somatório de cores, conforme afirma o experimento de Isaac Newton com seu disco, onde a luz branca decomposta num prisma se decompõe nas cores do arco-íris. Ou seja, no somatório de cores todas se anulam para que o branco apareça desse modo, a criança parece interpretar que o branco se traduz em "ausência de estímulos" e o que elas percebem é a presença da dor, do sofrimento emocional e físico; do "castigo" prometido pelo familiar por não ter obedecido.

O branco nega uma identidade, a uniformidade do branco nega as emoções que são expressas em cores. As cores trazem segurança, trazem vida, são estímulos intensos averbais e é tudo o que a criança precisa, o mundo tem cor, tem vida, elas trazem para criança a familiaridade com o ambiente de casa e pessoas que a criança já conhece, com algo que a criança já conhece. Inclusive permite a ela fazer associações e aguçar a criatividade.

Este relato de observação de campo está baseado nos inúmeros casos reiteradamente que acontecem e são presenciados pelos profissionais de enfermagem e continuamente fortalecido com atitudes e palavras dos adultos. Este fenômeno vem sendo observado e o medo já é considerado uma necessidade humana básica, na qual já está incluída na sistematização NANDA, NIC e NOC, mas, no entanto, na prática, ainda é reproduzido cada vez mais o fortalecimento cultural do medo do hospital, o medo do profissional de enfermagem e o medo do jaleco branco desde a idade mais tenra.

O conflito da representação em que a criança faz do jaleco branco na emergência pediátrica, a criança leva para todo e qualquer ambiente onde o procedimento doloroso é possível acontecer, quer seja no posto, na ação básica, quer seja em meio hospitalar, mesmo em cuidados indolores, como aferição de temperatura, percebe-se que a presença do profissional com jaleco branco desencadeia a dor emocional, mesmo sem a dor física e até o fenômeno, pois o jaleco branco está associado à possibilidade de dor e de sofrimento no cuidado.

\subsection{MANIFESTAÇÕES DA CRIANÇA DE MEDO E SOFRIMENTO DO FENÔMENO NA PRESENÇA DO JALECO BRANCO.}

Percebe-se que o sofrimento infantil é algo inevitável, mas que pode ser atenuado e minimizado pelos profissionais envolvidos e pela família. Durante o procedimento doloroso, a criança apresenta luta com quem estiver perto e a segurando, sofre, quer fugir nas palavras e na ação, sente primeiro a dor emocional e depois a dor física, profere palavras e frases que deixam os adultos sensibilizados, 
principalmente o profissional de enfermagem por exprimirem sua dor e seu sofrimento, quando estes são inevitáveis.

A criança entra num processo em que a crise adrenérgica é classicamente visualizada, a maioria dos procedimentos, com seus sinais e sintomas, que são: taquicardia, queda da saturação, sudorese, palidez cutânea/ rubor facial, liberação de esfíncter, alteração da ração, e sem falar no choro e nos gritos que já é uma reação esperada. Pode ser uma reação de fuga, reação de retração, reação de negação, reação de precaução, reação de inibição. Tais reações fazem parte de outros complexos emocionais, mas dotadas de diferentes configurações. A caracterização de medo não é simples e nesse viés, seria diferente de outras emoções parecidas, de terror, de susto, de pavor. É uma tentativa de pensar a emoção a partir desse olhar, que não pode destacar ou minimizar a importância do aspecto social ${ }^{(7)}$.

\subsection{O FENÔMENO DO JALECO BRANCO NA EMERGÊNCIA PEDIÁTRICA}

O discurso fenomenológico pretende corresponder à encarnação do sentido em seus diversos lugares de manifestação, através da história. Uma palavra, uma frase, uma definição, nunca poderão dizer o que há a dizer. Temos necessariamente de recorrer ao discurso para nos aproximarmos o mais possível da densidade semântica do fenômeno humano ${ }^{(5-8)}$.

No sofrimento da criança, percebe-se que a maioria tem o conhecimento e o reconhecimento do medo e da experiência dolorosa com a aproximação da pessoa de branco e ou presença, mesmo que seja para realizar um procedimento indolor, como: aferir a temperatura axilar, e até conversar com o familiar. Parece haver um sentimento de desconfiança, temor, ou seja, parece haver analogia da pessoa de branco com a dor, de alguém que vai causar a dor. A partir daí, percebe-se manifestações de protesto, luta e fuga, face com rubor choro inicialmente sem lágrima, mas se não for desconstruída a ideia da possibilidade da dor, as lágrimas e o choro acontecem sem a presença da dor, apenas a possibilidade interpretada pela criança da presença do profissional com jaleco branco.

Este comportamento de extremo medo e sofrimento, nos leva ao questionamento a respeito da constante conduta ameaçadora dos adultos sobre as crianças em relação aos profissionais de enfermagem que cuidam e praticam procedimentos dolorosos, de como o excesso de medo pode influenciar no amadurecimento emocional da criança, se existe ligação com este fenômeno e a síndrome do jaleco branco em adultos, inclusive no aparecimento de fobias e doenças psicossomáticas ao longo de sua vida.

Ainda complementa suas ideias afirmando que, para se entender todos os momentos do fenômeno é preciso que o que o discurso fenomenológico seja significante, pertinente, relevante, provocante e suficiente ${ }^{(5-8)}$.

Percebe-se que por mais que se tente com atitudes mais humanas que aliviam o sofrimento da criança, quando o familiar tem uma conduta que vai de encontro ao que a equipe de enfermagem faz para 
aliviar o medo, além de dificultar e prolongar o procedimento, este desencontro de informações deixa a criança confusa e descrente em ambos. Por este motivo, sensibilizar o familiar para ter uma conduta diferente, utilizando a técnica de reforço positivo, na qual é encorajadora e fortalece as atitudes da criança com elogios, é primordial e determinante para que este seja um parceiro no cuidado emocional.

Nota-se, que quando é realizada a explicação pelos familiares sem inverdades e fantasias de tudo que vai acontecer com a criança, quando ela vai ao hospital, na possibilidade dela precisar ser ao procedimento doloroso, e solicitar a ajuda e colaboração dela, é perceptível que esta sofre menos e colabora mais com o procedimento. $\mathrm{O}$ enfrentamento de crianças que os pais previamente conversam sobre o que pode acontecer quando vão ao hospital, é um facilitador no procedimento e no entendimento da criança a respeito da necessidade do procedimento. O diálogo fortalece a confiança da criança na família, nos profissionais de enfermagem e no estado de resiliência que precisa ser amadurecido.

\subsection{O MEDO QUE A FAMÍLIA SENTE NA EMERGÊNCIA PEDIÁTRICA.}

O medo sinalizado pelas mães nos leva refletir sobre o significado existente no jaleco branco para a criança e também para o familiar. Sabe-se que o branco é a ausência de cores, portanto ausência de estímulos visuais, pois as cores integram o mundo ajudando na distinção de objetos e fenômenos. Ao ver o jaleco branco ocorre a analogia à dor, medo, sofrimento que ela já conhece e que é inevitável. Pensava-se que a síndrome do jaleco branco só se manifestasse em adultos, no entanto, foi observado este fenômeno em crianças de forma bem clara, o medo extremo do profissional com jaleco branco. Da mesma forma, foi identificado comportamento diferente e mais tranquilo, mais cooperativo com profissionais sem o jaleco. Todas as mães perceberam e identificaram o medo do jaleco branco pela criança.

\subsection{ESTRATÉGIAS DE ENFRENTAMENTO DA SÍNDROME DO JALECO BRANCO EM CRIANÇAS.}

Como estratégias de abordagens em âmbito pediátrico, sugerimos o uso de jalecos que sejam coloridos, o uso da música e de cantigas infantis, fantoches e de brinquedos que possam desviar o foco da atenção, aos lactentes oferecer o dedo de luva com glicose para sugar. Em relação a crianças maiores, podemos conversar sobre atualidades, para meninos, carros e esportes, já menina, músicas, estética e beleza, etc. Desviar o foco da dor parece ser uma estratégia viável e possível. Estas são apenas algumas atitudes que podemos ter e lançar mão no dia a dia, pois são viáveis aos serviços de pediatria, ou seja, conversar com eles interagir antes, durante e depois de todo procedimento a ser realizado. O encorajamento em suas atitudes, é uma forma de apoiá-la e de confiança na sua participação no processo, elogiá-la em sua conduta é um diferencial que pode e deve ser incentivado, visando à segurança emocional e/ou profissional e a sua futura colaboração em procedimentos futuros. 


\section{DISCUSSÃO}

Percebe-se que o medo é uma emoção e uma experiência que é vivida desde o início da vida. Dessa forma, ele tem seu caráter de preservação da vida, quando se encontra em equilíbrio, no entanto a exacerbação deste pode ser paralisante e até dar margem ao aparecimento de fobias e de doenças psicossomáticas. Entende-se que apesar de ser uma emoção, o choro também é aprendido, principalmente no meio familiar, através das diversas formas.

Nas entrelinhas da observação participante, percebe-se que os familiares reproduzem nas crianças a exacerbação do medo, com palavras, atitudes que exprimem o "seu próprio medo", no qual foi identificado o fenômeno do jaleco branco em crianças, tanto através das falas com a criança e com os profissionais de enfermagem. Nas observações de campo percebe-se que as crianças apresentaram descompensação física e emocional.

O que leva aos seguintes questionamentos: que influências trazem a imposição da cultura do medo às crianças submetidas aos procedimentos dolorosos no aparecimento de fobias e de doenças psicossomáticas? Que influências trazem a imposição da cultura do medo no aparecimento da síndrome do jaleco branco na fase adulta? Até que ponto, impor o medo como forma de controle e de domínio da criança pelo adulto, pode prejudicar a criança e reforçar a reprodução do medo? Estes questionamentos inquietam os profissionais e nos levam a lançar mão de abordagens alternativas que atenuem este fenômeno.

A articulação da ludicidade, da musicoterapia, a sucção da luva com glicose, a luva inflada, entre outras, de acordo com a faixa etária, seguramente mostram que são ferramentas eficientes e eficazes na dispersão do foco do medo da dor física e emocional durante o procedimento invasivo. A implementação dessas abordagens humanas promovem o encorajamento do estado de resiliência, fortalecendo a estrutura emocional da criança, a fim de que ela se torne um adulto resiliente, capaz de gerenciar conflitos, sem que, com isso, tenha traumas, fobias, síndromes e doenças psicossomáticas.

\section{CONCLUSÃO}

Cabe aos profissionais de enfermagem reconstruir a sua própria imagem frente à criança e sua família, desviando o foco para a doença que é má e a causa e o motivo de estar ali, ela é quem produz sofrimento físico e emocional, causa sequelas, prejuízos à saúde e leva à morte. Atenuar a dor emocional pode diminuir consideravelmente, o sofrimento físico e facilitar a abordagem da equipe no momento do cuidado de enfermagem.

No tocante à vestimenta, sugerimos o uso do jaleco colorido, no qual ofereça estímulos através das cores, com adesivos bordados, brinquedos pendurados, de forma a desviar a atenção e tirar o foco do procedimento. Os ambientes que envolvem crianças precisam ter estímulos visuais, sonoros, brinquedos, 
jogos e atividades que envolvam tanto as crianças quanto a família. São recursos como estes que reduzem o estresse e a frieza que o hospital representa.

Ele também favorece a desconstrução da cultura do medo existente na sociedade, a respeito do profissional de enfermagem, na qual é associado à imagem da dor e do sofrimento desde a tenra idade. Ele também favorece a desconstrução da cultura do medo existente na sociedade, tendo como meio a educação em saúde para informar a criança da realidade dos acontecimentos e a função do profissional de enfermagem, no qual é associado à imagem da dor e do sofrimento desde a tenra idade.

Almeja-se suscitar reflexões a respeito da postura dos adultos frente ao medo da criança aos procedimentos dolorosos, e promover um ambiente e conduta encorajadora frente à dor e ao sofrimento, como forma de fortalecimento do estado de resiliência da criança, assim como, o seu fortalecimento emocional, prevenindo assim, doenças psicossomáticas e a síndrome do jaleco: profissionais adotem jalecos coloridos, abordagens mais lúdicas (músicas, brinquedos, entre outros), palavras e frases encorajadoras, agradecer o empenho da criança em colaborar nos mínimos detalhes e quando esta tiver alta, encorajar o desempenho dela durante a hospitalização e explicar o motivo de toda ação e que tudo o que foi realizado, contribuiu para que ela fosse embora restaurada da doença.

Por se tratar de grupo vulnerável e ter algumas limitações, justifica fomentar mais estudos e reflexões, merecendo mais atenção para redução do sofrimento emocional no tocante à família e às crianças hospitalizadas, visto existirem poucos estudos que retratem este fenômeno e estratégias como forma de enfrentamento no processo de trabalho.

Espera-se, com o estudo, contribuir com a otimização do cuidado à criança mediante a colaboração do familiar, levando em consideração que a família contribui na formação individual, pois imprime valores culturais, hábitos e sentimentos. Sendo o medo um sentimento dos mais primitivos, que vem sendo reforçado em demasia, principalmente, em se tratando dos procedimentos invasivos, anseia-se evitar a produção de fobias e iatrogênicas geradas na reprodução da cultura do medo, embutido em gestos, palavras e ações antes, durante e após os procedimentos dolorosos no setor de emergência e em demais serviços de pediatria. 


\section{REFERÊNCIAS}

${ }^{1}$ Biblioteca Virtual em Saúde - BVS. Descritores em Ciências da Saúde. Lista de significados - DeCS Server- list Exact. Biblioteca Virtual em Saúde - BVS. Descritores em Ciências da Saúde. Lista de significados - DeCS Server- list Exact.

2 Centro de Excelência para o Desenvolvimento na Primeira Infância GRIP - Université de Montréal P.O.Box 6128, succursale Centre-ville Montréal (Québec) H3C 3j7 Telefone: 514-343-6111, r. 5378 Fax: 514-343-6962 e-mail: cedje-ceecd@umontreal.casite: www.excellence-earlychildhood.ca

${ }^{3}$ Whaley LF, Wong DL. Enfermagem Pediátrica: elementos essenciais à intervenção efetiva. 2. ed. Rio de Janeiro: Guanabara Koogan; 1989.

${ }^{4}$ Capalbo, C. Consideração sobre o método fenomenológico e a enfermegem. Em pauta - Revista de Enfermagem da UERJ, Rio de Janeiro, v.2, n.2, p.192-97, out. 1990.

${ }^{\mathbf{5}}$ Figueiredo, Nébia Maria Almeida. Método e metodologia da pesquisa científica. $3^{\text {a }}$ edição Editora, Yendis - São Caetano do Sul - São Paulo, 2009.

${ }^{6}$ Dias F. N. O medo social e os vigilantes da ordem emocional. Lisboa, Portugal: Instituto Jean Piaget; 2007.

${ }^{7}$ Solomon R. C. The cross-cultural comparison of emotion. In: Marks J, Roger TA.Emotions in Asian Thought. Albany: State University of New York Press; 1995. p. 253-94.

${ }^{8}$ Rezende, A. Concepção fenomenológica da Educação. São Paulo: Cortez, 1990.

${ }^{9}$ Ministério da Saúde (BR). Cartilha do HumanizaSUS. Política Nacional de Humanização. A humanização como eixo norteador das práticas de atenção e gestão em todas as instâncias do SUS. Brasília: Ministério da Saúde; 2004.

${ }^{10}$ Arruda A. Representações Sociais: estudos selecionados. Paraná: PUCPR; 2014.

${ }^{11}$ Counselling for Patients and Family Members: A Follow-Up Study in the Emergency Department Eija Paavilainen, Mari Salminen-Tuomaala, Päivi Leikkola

ISRN Nurs. 2012; 2012: 303790. Published online 2012 September 12. doi: 10.5402/2012/303790

12 Caring in pediatric emergency nursing. Gillespie GL, Hounchell M, Pettinichi J, Mattei J, Rose L.Res Theory Nur Pract. 2012;26(3):216-32.

13 Emergency Department Experiences of Acutely Symptomatic Patients with Terminal Illness and Their Family Caregivers Alexander K. Smith, Mara A. Schonberg, Jonathan Fisher, Daniel J. Pallin, Susan D. Block, Lachlan Forrow, Ellen P. McCarthyJ Pain Symptom Manage. Author manuscript; available in PMC 2011 June 1.Published in final edited form as: J Pain Symptom Manage. 2010 June; 39(6): 972981. doi: 10.1016/j.jpainsymman.2009.10.004

${ }^{14}$ Improving parent-provider communication in the pediatric emergency department: results from the clear and concise communication campaign.Porter SC, Johnston P, Parry G, Damian F, Hoppa EC, Stack AM.Pediatr Emerg Care. 2011 Feb;27(2):75-80. doi: 10.1097/PEC.0b013e3182094283. 
15 Impact of patient and family communication in a pediatric emergency department on likelihood to recommend. Johnson MB, Castillo EM, Harley J, Guss DA.Pediatr Emerg Care. 2012 Mar;28(3):243-6. doi: 10.1097/PEC.0b013e3182494c83. 